\title{
Studies on the Arterial Vasculature in the Floor Region of the Mouth and the Submandibular Region of the Crabeating Monkey Using the Plastic Injection Method
}

\author{
By \\ Toshiaki NAKAJIMA \\ The 2nd Department of Oral Anatomy, Josai Dental University, \\ Sakado, Saitama 350-02, Japan \\ (Director: Professor H. Hanai) \\ -Received for Publication, November 5, 1983 -
}

Key Words: Artery, Mouth floor, Crabeating monkey, Plastic injection

Summary: The arterial vasculature in the floor region of the mouth and the submandibular region of the crab-eating monkey was studied by the acrylic plastic injection method.

1. The titled regions were found to be supplied by the hyoid branch and the sublingual artery arising from the lingual artery, and the submandibular glandular branch, the mylohyoid branch and the submental artery from the facial artery.

2. The hyoid branch supplied the mylohyoid and geniohyoid muscles.

3. The sublingual artery sent off the following branches: (1) the genioglossal branch to the genioglossus muscle, (2) the alveolingual artery to a wide area in the floor region of the mouth including several muscles, the sublingual gland and the gingiva and mucosa of the lingual side of the premolar area, (3) the sublingual papillary branch to the papilla, (4) the incisive gingival branch to the lingual gingiva of the lower incisors and canine, (5) the alveolar branch to the lower incisors, and (6) the median inferior labial artery to the lower lip and labial gingiva of the lower incisors. gland.

4. The submandibular glandular branch of the facial artery supplied the submandibular

5. The mylohyoid branch supplied the mylohyoid and digastric muscles and the lingual gingiva of the lower molars.

6. The branches of the submental artery were as follows: (1) the submandibular lymph node branch to the lymph nodes and the skin and muscles in the submandibular region, (2) the digastric branch to the digastric muscle, and (3) the gingival branch to the labial gingiva opposite the canine and lower lateral incisors.

The floor region of the mouth and the submandibular region are very important in oral surgery, particularly in various fields of medicodental research. Each of these regions represents a narrow area which is constructed from various kinds of tissues and organs in complicated situations and relations. The arterial vasculature in the regions thus shows a very complicated aspect three-dimensionally.
The arterial distribution in the regions has been studied in detail previously by Otsuka in the rat ('79), by Hanai in the guinea-pig ('80), and by Nakajima et al. in the rabbit ('82).

Concerning the arterial supply of the monkey head, reports of several investigations are available: on the general arterial system of the head by Dyrud (44), Hill ('53), Castelli et al. ('65) and Hartman et al. 
('69); on the arterial supplies of the maxillary sinus and its vicinity by Matsukawa ('69); on the facial artery by Hanai et al. ('76); on the arterial distribution of the lips by Hanai et al. ('75); on the arterial distribution of the lower gingiva by Hanai et al. ('74); and on the arterial supply of the submandibular gland by Yamamoto ('79). However, as regards the floor region of the mouth and the submandibular region no detailed report is yet available.

The present study was undertaken to elucidate in detail the origins, ramifications, distributions and anastomoses of the distributing arteries in the titled regions of the crab-eating monkey, employing the acrylic plastic injection method.

\section{Materials and Methods}

Thirty-nine adult crab-eating monkeys (Macaca cynomolgos) were used. After exsanguination, the heads of the animals were injected with colored acrylic plastic into the carotid arterial system. Thirtyfour of the injected heads were macerated with $20 \% \mathrm{NaOH}$ solution to obtain corrosion casts and the remaining 5 heads were embalmed in 10\% formalin solution for dissection. The specimens were dissected and observed under a binocular magnifier.

\section{Observations}

The floor region of the mouth and the submandibular region of the crab-eating monkey were supplied by the hyoid branch and the sublingual artery arising from the lingual artery and the submandibular glandular branch, the mylohyoid branch and the submental artery from the facial arteries of the external carotid. In 14 of the 61 cases observed, the medial pterygoid branch (Figs. $2 \& 20$ ) from the maxillary artery was distributed to the posterosuperior part of the mylohyoid muscle as a supplier of the regions.

The lingual artery and the facial arose once in a common stem (about $1.22 \mathrm{~mm}$ ) from the external carotid artery as its first branch (Fig. 3). The stem arose forwards from the anterior wall or anteromedial wall of the external carotid at the level of the atlanto-occipital joint. It ran forwards for $5-15 \mathrm{~mm}$ medial to the medial pterygoid muscle superomedial to the posterior belly of the digastric and then bifurcated into the lingual artery and the facial. The common stem gave off the superior thyroid in its course. This artery supplied the pharynx, larynx, thyroid gland, bronchi, hyoid bone, hyoid muscles, styloglossus muscle, etc. However, it did not send any branch to the titled regions.

\section{A. Lingual artery}

The lingual artery (about $0.94 \mathrm{~mm}$ ) (Figs. $1 \& 3$ ) ran forwards medial to the medial pterygoid muscle inferomedial to the styloglossus, keeping the course of the common stem. In the tongue, it advanced further between the styloglossus and the stylohyoid muscles, and curved upwards to be continued by the deep lingual artery, after giving off the sublingual artery. The deep lingual artery ran towards the tip of the tongue lateral to the genioglossus muscle, giving off the dorsal lingual branches.

The lingual artery sent off the following branches to the floor region of the mouth and the submandibular region.

\section{Hyoid branch}

This branch (about $0.38 \mathrm{~mm}$ ) (Figs. $1 \&$ 3 ) originated forwards from the inferior wall of the lingual artery lateral to the hyoid bone and passed forwards and downwards along the outside of the hyoid bone to near its anterior end. It next advanced between the genioglossus muscle and the mylohyoid, and was finally distributed chiefly to the 
posterior half of both the muscles. In 8 of the 61 cases observed, there was no hyoid branch. In 2 of these 8 cases, the regions were supplied by the hyoid branch of the opposite side. In the remaining 6 cases, the region was supplied by the alveolingual artery from the sublingual artery.

\section{Sublingual artery}

This artery (about $0.60 \mathrm{~mm}$ ) (Figs. 1 \& 6) arose forwards and downwards from the anteroinferior wall of the lingual artery opposite the molar part. The sublingual passed forwards and downwards lateral to the genioglossus muscle, entered the symphyseal foramen in the median part of the mandible along with the same artery of the opposite side. Next, the artery of either the right or the left side terminated in the incisive alveolar part to supply it. The artery of the opposite side which passed through the foramen, appeared in front of the mandibule to ascend for the lower lip (right 14 cases, left 15 cases). In 5 cases, the sublingual artery did not enter the symphyseal foramen. In another one case, the sublingual arteries on both sides appeared for the lower lip, passing through the foramen.

The sublingual artery sent off the following branches.

\section{a. Genioglossal branches}

These branches $(0.05-0.25 \mathrm{~mm})$ (Figs. $1 \& 7)$ which numbered 8 to 13 , arose either upwards or downwards from the superior, medial and inferior walls of the sublingual artery. They ran upwards or downwards lateral to the genioglossus muscle to supply it. The branches arising near the symphyseal foramen additionally supplied the anterior part of the geniohyoid and mylohyoid muscles.

\section{b. Alveolingual artery}

This artery (Figs. 1, 4, $6 \& 13$ ) was observed to arise either from the sublingual artery, the lingual artery or the facial artery depending on the individual. The artery could thus be divided into three types:

Type I (in 28 of the 61 cases): In this type, the alveolingual artery arose from the sublingual artery. The sublingual in this type was well-developed, arose from the lingual more posteriorly and had a wide distributing territory.

The alveolingual artery (about $0.41 \mathrm{~mm}$ ) (Figs. $1 \& 6$ ) arose forwards and downwards from the inferior wall of the sublingual artery superior to the sublingual gland. It passed downwards or forwards medial to the gland to the lower edge. In this course, it gave off the sublingual glandular branches to the gland. In 3 of the 28 cases, the alveolingual artery was not observed. In these cases, the sublingual glandular branches (numbering 2-5) arose directly from the sublingual artery.

The artery in this type sent out the following branches.

\section{1) Genioglossal branches}

These branches $(0.05-0.15 \mathrm{~mm})$ (Figs. $1 \& 6)$ which numbered 1 to 3 , arose forwards and upwards from the medial or anterior wall of the alveolingual artery. They supplied the genioglossus muscle.

2) Submandibular ductal branches

These branches (about $0.10 \mathrm{~mm}$ ) (Fig. 1 ), numbering 1 or 2 , originated forwards or backwards from the medial wall of the alveolingual artery. They advanced along the submandibular duct to supply the middle part of it.

3) Sublingual glandular branches

These branches $(0.05-0.15 \mathrm{~mm})$ (Figs. $1 \& 6$ ) arose from the alveolingual artery to enter the gland from its medial side to supply it.

4) Mylohyoid branches

These branches (about $0.15 \mathrm{~mm}$ ) (Fig. 1) which numbered 2 or 3 , originated from the lateral wall of the alveolingual artery at variable loci except near the origin and 
entered the mylohyoid muscle to supply its central part.

5) Gingival branches

These branches $(0.05-0.15 \mathrm{~mm})$ (Fig. 1) which numbered 2 or 3 , were further upward extensions of the mylohyoid branches after they had sent off their muscular twigs. They reached the lingual gingiva opposite from the premolars to the molars.

Type II (in 20 of the 61 cases): In this type, the alveolingual artery arose from the lingual. The sublingual artery frequently originated more anteriorly and was less developed than in type I. The alveolingual artery (about $0.48 \mathrm{~mm}$ ) (Fig. 4) arose at a more posterior part compared to type I. It originated forwards and downwards as the third branch from the inferior wall of the lingual artery lateral to the anterior end of the hyoid bone opposite the first molar or second molar with a more posterior origin than in type $I$. The alveolingual artery ran forwards and downwards for 2-3 $\mathrm{mm}$ lateral to the hyoglossus muscle to reach the superomedial end of the sublingual gland. Next, it advanced downwards between the sublingual gland and the geniohyoid muscle to reach the inferior edge of the sublingual gland, where it changed direction anteriorly. It then ran forwards along the lower edge of the gland and finally supplied the gland with the sublingual glandular branch. In 2 of the 20 cases, the alveolingual artery was further developed, continuing to the submental part passing through the digastric muscle.

The alveolingual artery in this type sent off the following branches.

\section{1) Hyoglossal branch}

This branch (about $0.05 \mathrm{~mm}$ ) (Fig. 4) arose forwards and upwards from the superomedial wall of the alveolingual artery near its origin. It passed along the hyoglossus muscle to supply this muscle.
2) Submandibular ductal branches

These branches (Fig. 5), numbering 1 or 2 , revealed almost the same course and distribution as those in type I.

3) Geniohyoid branches

These branches $(0.05-0.20 \mathrm{~mm})$ (Fig. 4) which numbered 2 or 3 , arose from the alveolingual artery between the geniohyoid muscle and the sublingual gland towards the geniohyoid muscle located medial to the gland to supply this muscle. In 4 cases, the first branch among them was large, and proceeded between the geniohyoid and mylohyoid muscles to supply both muscles widely.

4) Mylohyoid branches

5) Sublingual glandular branches

6) Gingival branches

4), 5) and 6) had similar features to those in type I.

Type III (in 13 of the 61 cases): The alveolingual artery arose from the facial artery. The alveolingual (about $0.50 \mathrm{~mm}$ ) (Fig. 13) in this type was the largest and arose the most posteriorly among the three types. The artery originated forwards and upwards from the anterosuperior wall of the facial artery as the latter artery ran forwards and downwards near the posteroinferior end of the mylohyoid muscle as the second branch of the facial artery. On turning forwards between the digastric and medial pterygoid muscles, the alveolingual passed forwards on the superior face of the mylohyoid muscle beyond the posterior end of the sublingual gland to supply the gland. In this type, the hyoid branch, the sublingual artery deriving from the lingual artery and the mylohyoid branch deriving from the facial artery were comparatively small. In one case only, this artery arose from the submandibular glandular branch and in another one case, it was large and 
extended to the submental part.

The alveolingual artery in this type sent off the following branches.

\section{1) Mylohyoid branches}

These branches which numbered 4 to 6 , showed features similar to those in types I and II. However, two characteristic branches were observed among the mylohyoid branches in type III. One of them (about $0.28 \mathrm{~mm}$ ) (Fig. 14) arose forwards and downwards from the inferomedial wall of the alveolingual artery before it entered the medial side of the mylohyoid muscle to supply the posteroinferior part of the mylohyoid muscle. The other branch (about $0.20 \mathrm{~mm}$ ) (Fig. 14) originated forwards and upwards from the superior wall of the alveolingual artery near the posterior end of the insertion of the mylohyoid muscle and passed towards the lateral surface of the dorsum of the tongue, branching off the mylohyoid branch to supply it. From the mylohyoid branch, the submandibular ductal branch was given off in 3 cases.

2) Subiingual glandular branches

3) Goniohyoid branches

4) Gingival branches

2), 3) and 4) were similar to those observed in other types.

\section{5) Digastric branch}

This branch (about $0.10 \mathrm{~mm}$ ) originated from the alveolingual near the anteroinferior end of the sublingual gland and descended between the mylohyoid muscle and the mandibular bone finally to supply the anterior part of the digastric muscle.

\section{c. Sublingual papillary branches}

These branches (about $0.10 \mathrm{~mm}$ ) (Figs. 1 $\& 8$ ), numbering 1 to 4 , arose from the superior or lateral wall of the sublingual artery as it crossed the submandibular duct. They passed forwards along the submandibular duct to supply almost the anterior half of the duct, the sublingual papilla and the adjacent alveolar mucosa. In 12 cases ( 2 cases of type I, 5 cases of type II, 5 cases of type III), this branch arose from the alveolingual artery.

\section{d. Incisive gingival branches}

These branches (about $0.24 \mathrm{~mm}$ ) (Figs. $1 \& 9)$ which numbered 1 or 2 , originated from the superior wall of the sublingual artery just before it entered the symphyseal foramen. The branches first ascended along the medial face of the mandible, reached the lingual gingiva opposite the incisors and curved lateralwards. They next coursed posterolaterally along the gingival edge, and finally anastomosed with a branch which appeared from a nutrient foramen near the lingual alveolar edge opposite the first premolar or canine to form an upward arterial arch. From this arch, about 8 branches departed in a brush shape towards the gingiva opposite the premolar and incisor to supply it. In 9 cases, the branch arose from the alveolingual artery.

\section{e. Alveolar branches}

These branches $(0.20-0.25 \mathrm{~mm})$ (Figs. 1 $\& 10$ ), numbering 2 to 4 , arose upwards or downwards from the superior or inferior wall of the sublingual artery within the symphyseal foramen. They ascended in the bone to the alveoli to supply the periodontal membrane and pulp of the incisors.

\section{f. Median inferior labial artery}

This artery being a direct continuation of the sublingual artery was observed on either side, the right or left. The median inferior labial artery (about $0.48 \mathrm{~mm}$ ) (Figs. $1 \& 11$ ) which appeared through the symphyseal foramen, ascended in the median part of the mentum and lower lip, giving off twigs to the subcutis in this part and to the labial gingiva opposite the lower incisors. On reaching the inferior labial edge, the artery split into the right and left inferior labial 
branches in a T-shape, to supply the lower lip.

\section{B. Facial artery}

The facial artery (about $0.98 \mathrm{~mm}$ ) (Figs. 2, $3 \&$ 12) separated from the common trunk with the lingual, passed forwards and downwards between the thyrohyoideus and digastricus muscles, crossing the hypoglossal nerve medial to the medial pterygoideus and emerged onto the face, turning upwards around the mandibular border in front of the anteroinferior edge of the masseter above the submandibular gland. In one case of the 61 , the facial artery was lacking, being compensated for by the transverse facial artery.

All the branches distributing to the floor region of the mouth and the submandibular region among branches of the facial artery, arose from the cervical part of the artery. The branches to these regions were as follows.

\section{Submandibular glandular branch}

This branch (about $0.61 \mathrm{~mm}$ ) (Figs. $2 \&$ 12) originated backwards and downwards from the lateral or inferior wall of the facial artery $10-15 \mathrm{~mm}$ peripheral to its origin after it had sent off the ascending palatine artery and the medial pterygoid branch. The branch reached the submandibular gland to supply it, passing through between the mandible and the digastric muscle. In 4 of the 61 cases observed, it arose from the lingual artery. In another case, it arose from the alveolingual artery in type III. In 9 cases, 2 glandular branches were observed, and in 6 cases, the branches numbered 3 .

\section{Mylohyoid branch}

This branch (about $0.45 \mathrm{~mm}$ ) (Figs. 2 \& 15) arose from the superior wall of the facial artery medial to the anteroinferior border of the medial pterygoid muscle about $5 \mathrm{~mm}$ distal to the origin of the submandibular glandular branch between the mandible and the digastric muscle. The branch ran forwards and upwards to the inferior face of the mylohyoid muscle, and then proceeded forwards in the space bounded by the mandible, the digastric muscle and the mylohyoid to the anterior end of the floor region of the mouth, forming an upward arch. In its course, it sent off superiorly running and medially running branches for the mylohyoid muscle to supply it. In 2 of the 61 cases observed, the mylohyoid branch arose from the submandibular glandular branch. In 2 other cases, it arose from the submental artery.

The mylohyoid branch sent off the following branches for the floor region of the mouth and the submandibular region.

a. Digastric branches

These branches (about $0.10 \mathrm{~mm}$ ) (Figs. 2 $\& 15$ ), numbering 2 to 4 , arose from the mylohyoid branch and ran medialwards to supply the digastric muscle.

b. Molar gingival branches

These branches (about $0.05 \mathrm{~mm}$ ) (Figs. 2 $\&$ 16) which numbered 2 to 4 , and were no more than upwards extensions of the mylohyoid branch, ascended along the mylohyoid muscle to the molar gingiva. They supplied the lingual gingiva opposite the second and third molars in a fork shape.

In 2 of the 61 cases observed, the mylohyoid branch sent off a branch which appeared at the subcutis of the submental region through the digastric muscle. In 7 cases, the posteriormost one of the branches which supplied the posterior part of the mylohyoid muscle, arose directly from the facial artery. Further, in 2 cases, the mylohyoid left from the submandibular glandular branch.

\section{Submental artery}

This artery (about $0.40 \mathrm{~mm}$ ) (Figs. 2, 17 $\& 18$ ) originated forwards from the inferomedial wall of the facial artery as it turned 
upwards around the mandibular edge towards the face. The submental passed forwards between the cutaneous muscle and the digastric, being accompanied by the mandibular marginal branch of the facial nerve, and divided into two or three. They then reached the mental part, where they anastomosed with branches from the median inferior labial artery. In 5 of the 61 cases observed, the submental artery arose from the mylohyoid branch. In 2 other cases, it originated from the submandibular glandular branch. Further, in 5 other cases, the submental artery terminated in the submandibular part, not extending to the mental part, and in such cases the cutaneous branch which arose from the facial artery, compensated for the submental artery in the supply of the mental part.

The submental artery sent off the following branches.

\section{a. Submandibular lymph node branch}

This branch (about $0.18 \mathrm{~mm}$ ) (Figs. $2 \&$ 18) arose from the medial wall of the submental artery $5-10 \mathrm{~mm}$ peripheral to the origin and reached the submandibular lymph node which was covered by the cutaneous muscle, to supply the lymph node in the form of fine twigs. A few twigs emerged again from the node, to supply the cutaneous muscle and the skin in the submandibular region. The lymph node branch arose from the masseteric branch of the facial in 5 of the 61 cases observed; from the mylohyoid branch in 2 cases; directly from the facial artery in one case; and from the submandibular glandular branch in another case.

\section{b. Digastric branch}

This branch (about $0.20 \mathrm{~mm}$ ) (Figs. 2 \& 19) arose forwards and medially from the medial wall of the submental artery. After 2-3 $\mathrm{mm}$, it bent forwards and entered the digastric muscle, splitting into two or three, to be distributed to a large part of the muscle.

c. Gingival branches

These branches (about $0.13 \mathrm{~mm}$ ), numbering 2 or 3 , originated from the submental artery in its upward course in the mental part, and ascended along the lateral surface of the mandible. They reached the labial gingiva opposite the canine and lower lateral incisor to supply it.

\section{Discussion}

The arteries supplying for the floor region of the mouth and the submandibular region in various animals have been reported by several authors. Miller et al. ('64) in the dog and Greene ('68) and Otsuka ('79) in the rat described the regions to be supplied only by branches of the facial artery. Craigie ('48), Bugge ('68), Godynicki ('76) and Nakajima et al. ('82) in the rabbit and Dyrud ('44) and Castelli et al. ('65) in the rhesus monkey reported the regions to be supplied by branches from the lingual and facial arteries. Hanai ('80) reported that they were supplied by branches from the lingual, facial and maxillary arteries (the alveolingual artery of the latter) in the guinea-pig. Gray ('64) and Kamijo ('68) stated that they were supplied by branches of the lingual, facial and maxillary arteries (the inferior alveolar artery of the latter) in man. In the present study on the crabeating monkey, the regions were supplied by branches of the lingual and facial arteries as in the rabbit, man and rhesus monkey.

In 14 of the 61 cases observed, the pterygoid branch of the maxillary artery which was distributed to the superoposterior part of the mylohyoid muscle joined in the supply of the region in addition to the lingual and facial arteries. However, the maxillary artery in the guinea-pig joined in the supply of the floor region through its alveolingual artery, differing from the crab-eating monkey. 
Table 1

\begin{tabular}{|l|c|c|c|}
\hline & Facial A. & Lingual A. & Maxillary A. \\
\hline Rat & 0 & & \\
Guinea-pig & 0 & 0 & 0 \\
Dog & 0 & & \\
Cat & 0 & & \\
Goat & 0 & 0 & \\
Rabbit & 0 & 0 & \\
Human & 0 & 0 & \\
Rhesus monkey & 0 & 0 & \\
Crab-eating monkey & 0 & 0 & \\
\hline
\end{tabular}

$O$ : Source of distributing arterial branches

\section{A. Lingual artery and its branches}

Previous works on the branches of the lingual artery distributed to the regions were summarized in Table 1.

In the present study on the crab-eating monkey, the sublingual artery and the hyoid branch were distributed to the same regions as in the rhesus monkey, rabbit and goat.

\section{Hyoid branch}

Okano ('60) found that the hyoid branches of the lingual artery supplied the floor region of the mouth in the rabbit, dog, cat and goat. Nakajima et al. stated that in the rabbit, 4 branches from the hyoid branch were observed and only 2 of them were distributed to the floor region. Bugge also stated that the hyoid branch in the rabbit arose from the lingual artery lateral to the hyoid bone to supply the genioglossus muscle.

In man, Gray and Kamijo designated the branch as the "suprahyoid branch" and described it as supplying the hyoid muscles. Hartman and Straus reported that in the rhesus monkey, it gave off branches to the pharynx and the hyoid muscles, while Dyrud showed it merely pictorially. In the present study, the hyoid branch was a muscular branch as described by Bugge and was found to originate lateral to the hyoid bone from the lingual artery and to pass forwards along the bone to supply mainly the geniohyoid muscle and the posterior part of the mylohyoid.

\section{Sublingual artery}

\section{$\S$ Origin and course}

Otsuka classified the sublingual artery of different animals into the "carnivora type" (dog, cat, rat, guinea-pig) and "human type" (man, cattle, goat, rabbit) according to its source. In the former type, the sublingual artery arose from the facial artery and the submental from the sublingual; in the latter, it arose from the lingual and the submental from the facial. The crabeating monkey belongs to the "human type". Those animals which belong to the "carnivora type" can be further classified into two types: type 1 (dog, cat) where the animals have the hyoid branch as a branch of the lingual artery, and type 2 (rat, guineapig) where the animals have no hyoid branch.

Castelli et al. stated that the sublingual artery in the rhesus monkey passed forwards in the deep region of the tongue, and next either on the right or left entered the lower lip passing through the symphyseal foramen to supply the lower lip and the labial gingiva 
in the incisal region. In the present study on the crab-eating monkey, the course of the sublingual artery closely resembled that in the rhesus monkey. However, there were some differences between the two kinds of monkey in that in the crab-eating monkey the sublingual arteries of both sides entered the mandibular bone in 10 of the 15 cases, and sent off a few branches to the incisors and adjacent area.

Also, the lingual in the crab-eating monkey differed from that in man in that the sublingual in the monkey passed through the mandible to reach the lower lip. In the rabbit (Okano, Bugge and Nakajima et al.), the sublingual artery displayed a closely similar course and branching pattern to the crab-eating monkey.

Okano stated that the sublingual artery in the goat took the same course as in the rabbit and its branches extended to the subcutis in the submandibular region, passing through the mylohyoid muscle. In the crab-eating monkey, no branch of the sublingual artery reached the subcutis.

As pointed out by Nakajima et al., the sublingual artery in the human type (including the crab-eating monkey) ran above the mylohyoid muscle to supply the muscle from its upper side, whereas in the carnivora type is advanced below the muscle to supply it from the inferolateral side.

\section{$\S$ Branches}

Genioglossal branches have also been found previously in the rabbit by Nakajima et al. The alveolingual artery described by Hanai in the guinea-pig was observed in the crab-eating monkey. In the guinea-pig, the artery derived from the maxillary artery, whereas in the crab-eating monkey it originated from any one of the sublingual, lingual or facial, and had a wider distribution than in the guinea-pig.

Castelli et al. reported the sublingual artery as being duplicated. Although Hanai et al. noted the existence of the accessory sublingual artery, those arteries appeared to correspond to the alveolingual artery in the present study.

As indicated by Hamano ('65), the sublingual glandular branch arose from the sublingual artery in the human fetus. In the rabbit also, the branch was reported by Nakajima et al. to derive from the sublingual artery. However, in the crab-eating monkey, the branches were given off from the alveolingual artery of the sublingual. Castelli et al. noted only that the sublingual artery in the rhesus monkey was distributed to the lingual alveolar mucosa and the attached and free gingiva. The present author found that the artery sent the sublingual papillary branch to supply the papilla, the submandibular duct and the adjacent alveolingual mucosa. No papillary branch was reported in the rat or rhesus monkey but was in the guinea-pig. In the rabbit, the branch was found by Nakajima et al. ('82) as a branch of the inferior labial artery.

The observations for the incisive gingival branch in the present study are in agreement with those reported by Hanai et al. Suzuki ('64) stated that in the human fetus, branches of the sublingual artery were distributed to the lower lingual gingiva. In the present study, similar findings were obtained.

In the rat (Otuska) and guinea-pig (Hanai), the periphery of the sublingual artery was found to divide into the preincisive and retroincisive branches. The former emerged onto the anterior surface of the mandible passing through the symphysis, while the latter ascended on the posterior surface of the mandible near the median to supply the lingual gingiva of the incisive part. Between the two branches, the preincisive one appeared to correspond to the median inferior labial artery, the terminus of the sublingual artery in the crab-eating monkey: and the retroincisive to the incisive gingival 
branch. Nakajima et al. did not find any branch which corresponded to the incisive gingival branch; and to the lingual gingiva in the incisive part, a branch from the inferior labial artery was distributed.

The alveolar branch of the sublingual artery in the crab-eating monkey appears to correspond to the symphyseal branch in the guinea-pig as regards position. However, they differ from each other in that the symphyseal branch in the guinea-pig does not supply the lower incisors but adjacent muscles and bone.

Ichikawa ('61) and Watanabe ('63) stated that in the human fetus, the sublingual artery gave off branches to the dental follicles of the incisors. According to Gray, Kamijo, Castelli ('63), the lower incisors are supplied by branches of the inferior alverolar artery. In the rhesus monkey, according to Castelli et al., the periodontal membrane and pulp of the lower permanent incisors are supplied by the sublingual artery, and the lower deciduous incisors by the inferior alveolar artery. In the present study, the sublingual artery supplied the lower permanent incisors as in the rhesus monkey. The sublingual artery in man is less developed and is distributed only to a restricted region of the floor of the mouth bordered by the bodies of the mandible on both sides. In addition, this artery in man is reduced in the changing period from deciduous teeth to permanent teeth, whereas in the crab-eating monkey the artery retains a wide distribution extending to the lower lip, the mental region and the lower permanent incisors.

\section{B. Facial artery and its branches}

Castelli et al. stated that the facial artery in the rhesus monkey passed downwards and forwards lateral to the hypoglossal nerve and the thyrohyoid muscle in contact with the lower part of the medial pterygoid muscle laterally, and then curved around the inferior border of the mandible to pass onto the face in front of the anterior fibers of the masseter muscle. In the present study, the artery revealed a closely similar course. The details of the course of the mandibular part of the facial artery in the rabbit (Nakajima et al.), dog (Miller et al.), rat (Otsuka) and guinea-pig (Hanai), were much the same as those in the crab-eating monkey.

As distributing vessels to the floor region of the mouth and the submandibular region among the branches of the facial, the submandibular glandular branch (Morinaga ('55), Takashima ('67), ('71)) and the digastric branch (Nakajima et al.) have been reported in the rabbit; the submandibular glandular branch (Irifune ('80)) and sublingual artery (Miller et al.) in the dog; the tonsillar artery (Otsuka and Greene), the sublingual artery (Otsuka) and the glandular branch (Greene) in the rat; only the sublingual artery (Hanai) in the guinea-pig; and the glandular branch and the submental artery (Kamijo, Gray) in man.

Hartman et al. described the branch to the submaxillary gland and the submental artery as branches from the mandibular part of the facial artery. Castelli et al. found the submandibular artery, the submental branch and the mylohyoid branch. In the present study, the submandibular glandular branch, the mylohyoid branch, and the submental artery were observed in the submandibular part.

1. Submandibular glandular branch

This branch was reported to derive from the posterior auricular, lingual, superior thyroid and external carotid arteries in addition to the facial in the dog (Miller et al., Irifune). In the rabbit (Morinaga), rat (Greene, Takashima) and mouse (Ban ('59)), its origin is only from the facial artery. In man (Kamijo ('66)), it arises 
mainly from the facial and submental arteries, and may also arise from the ascending palatine, external carotid, lingual, sublingual, hyoid and suprahyoid arteries. In the human fetus (Takashima), the main branch arises from the submental artery, and auxillary branch arises from the facial and ascending palatine arteries. In the crabeating monkey, the submandibular glandular branches numbered 2 or 3 and arose mainly from the facial artery, and additionally from the mylohyoid branch and the lingual artery. Yamamoto ('79) reported similar findings for the crab-eating monkey.

\section{Mylohyoid branch}

The description by Castelli et al. of the origin and course of the mylohyoid branch in the rhesus monkey is in agreement with the observations of the present author. Hanai et al. reported that the mylohyoid branch was distributed to the gingiva opposite the lower molars and the sublingual gland in addition to the mylohyoid muscle. However, the present author did not found any branch to the sublingual gland. The digastric branch of the facial artery reported by Nakajima et al. in the rabbit appeared to correspond to the mylohyoid branch in the crab-eating monkey, judging from its course and territory. The present author named the branch the "mylohyoid" since it was distributed mainly to the mylohyoid muscle rather than the digastric muscle.

\section{Submental artery}

In the present study, the facial artery sent off the submental. Castelli et al. reported that the submental artery in the rhesus monkey ran forwards along the inferior border of the mandible to be distributed mainly to the anterior digastric and platysma muscles. In the crab-eating monkey, Hanai et al. found this artery to be variable in its development: in certain cases it was less developed and supplied only its neighboring skin and part of the muscles, while in other cases it was welldeveloped and extended beyond the submental region, lower lip and gingiva. In the present study, the artery was seen to be developed as well as that reported by Hanai et al., and in addition it gave off a branch to the submandibular lymph nodes.

In the dog, cat, rabbit and human fetus, (Miyata ('66)) the submental artery has been reported to arise from the facial artery. In the guinea-pig (Miyata ('65)), the artery is reported to arise from the sublingual artery; and in the goat, mainly from the lingual. It was stated by Gray and Kamijo that the submental artery in man passed forwards between the mylohyoid and digastric muscles and finally anastomosed with the mental and inferior alveolar. arteries. However, in the present study, the artery ran lateral to the digastric muscle and had no anastomoses with those arteries.

\section{Acknowledgement}

The author wishes to express his thanks to Professor $\mathrm{H}$. Hanai for his expert guidance and encouragement.

\section{References}

1) Ban, F.: The study on the arterial distribution in the salivary gland of the mouse. J. Kurume Med., 22 : 3476-3496, 1959. (in Japanese)

2) Bugge, J.: The arterial supply of the rabbit nose and oral cavity. Acta Anat., 70: 168 $183,1968$.

3) Castelli, W.: Vascular architecture of the human adult mandible. J. Dent. Res., 42 : 786-792, 1963.

4) Castelli, W. A. and D. F. Huelke: The arterial system of the head and neck of the rhesus monkey with emphasis on the external carotid system. Am. J. Anat., 116 : 149-170, 1965.

5) Craigie, E. H.: Bensley's practical anatomy of the rabbit. 8th Ed., Phila., 292-295, 1948.

6) Dyrud, J.: The external carotid artery of the 
rhesus monkey (Macaca mulatta). Anat. Rec., 90: 17-22, 1944.

7) Godynicki, S.: Arteries in the head of the hare. Polsk Archiwum Weterynaryine, 19: 101-114, 1976.

8) Gray, H.: Gray's Anatomy, 33rd Ed., London, 782.791, 1964.

9) Greene, E. C.: Anatomy of the rat. Hafner Publ. Co., N. Y., 31-253, 1968.

10) Hamano, F.: The study on the arterial system in the salivary gland of the human fetus. II. The minute vessel of the salivary gland. J. Tokyo Dent. Col. Soc., 65: 122-138, 1965. (in Japanese)

11) Hanai, H., T. Wakida and A. Yamanaka: On the arterial supply to the lower gingiva and the adjacent mucosa of the crab-eating monkey. Bull. Josai Dent. Univ., 3: 25-29, 1974. (in Japanese)

12) Hanai, H., T. Hanai, H. Otsuka and A. Yamanaka: The arterial distribution of the lips in the crab-eating monkey by plastic injection method. Okajimas Fol. Anat. Jpn., 52: 85 102,1975 .

13) Hanai, H., T. Hanai, H. Otsuka and A. Yamanaka: On the facial artery and its branches in the crab-eating monkey. Bull. Josai Dent. Univ., 5: 13-20, 1976. (in Japanese)

14) Hanai, T.: Studies on the arterial vasculature in the floor region of the guinea-pig mouth using the plastic injection method. Okajimas Fol. Anat. Jpn., 57: 167-188, 1980.

15) Hartman, C. G. and W. L. Jr. Straus: The anatomy of the rhesus monkey. Hafner Publ. Co., N. Y., 48, 1969.

16) Hill, W. C.: The blood-vascular system of tarsius. Proc. Zool. Soc., 123: 655-694, 1953.

17) Ichikawa, $K .:$ On the distributing artery to the mandible of Japanese human fetus. J. Tokyo Dent. Col. Soc., 61: 481-511, 1961. (in Japanese)

18) Irifune, M.: The facial artery of the dog. Okajimas Fol. Anat. Jpn., 57: 55-78, 1980.

19) Kamijo, $Y .:$ The micro-circulation of the oral vicinity. Igaku no ayumi, 57: 366-376, 1966. (in Japanese)

20) Kamijo, Y.: Oral anatomy. 3, Angiologia, Anatom Co., Tokyo, 445-461, 1968. (in Japanese)

21) Matsukawa, M.: Stereological studies on several ducts and vessels by injection method of acrylic resin. XXI. On the posterior superior alveolar, the infraorbital and the spheno- palatine arteries of Macaca cynomolgos, laying emphasis on the maxillary sinus and its vicinity. Okajimas Fol. Anat. Jpn., 45: 197-223, 1969.

22) Matsukawa, M., A. Ryumon, H. Furuhara and S. Masuda: Stereological studies on the several ducts and vessels by injection method of acrylic resin. XXII. On the superficial temporal artery of Macaca cynomolgos. Okajimas Fol. Anat. Jpn., 45: 267-278, 1969.

23) Miller, M. E., G. C. Christensen and H. E. Evans: Anatomy of the dog. Saunders Co., Phila., 288-300, 1964.

24) Miyata, T., K. Kamakura and S. Kaneko: Stereological studies on several ducts and vessels by injection method of acrylic resin. $X V$. Distributing arterial branches of the submandibular lymph nodes in guinea-pig. Okajimas Fol. Anat. Jpn., 41: 221-225, 1965.

25) Miyata, T.: Stereological studies on several ducts and vessels by injection method of acrylic resin. XVI. Arterial distribution of the submandibular lymph nodes in some mammals. Okajimas Fol. Anat. Jpn., 42: 265-280, 1966.

26) Morinaga, Y.: The stereological studies on the arterial system of the salivary gland by the casting method of acrylic resin. V. On the arterial system of the salivary gland in the rabbit. Acta Schol. Med. Gifu, 3: 150-159, 1955. (in Japanese)

27) Nakajima, T., H. Hanai, T. Asano and K. Yasuda: Arterial distribution in the floor region of the rabbit mouth using the plastic injection method. Okajimas Fol. Anat. Jpn., 58: 235-246, 1982.

28) Nakajima, T., H. Hanai, Y. Okawa and F. Akizaki: The inferior labial artery and its branches in the rabbit. Bull. Josai Dent. Univ., 11: 311-316, 1982. (in Japanese)

29) Okano, H.: Cubical anatomy of several ducts and vessels by injection method of acrylic resin. VII. On the ramification of A. lingualis and its fine distribution in some mammals. Okajimas Fol. Anat. Jpn., 34: 233-297, 1960.

30) Otsuka, H.: Arterial distribution in the region of the floor of the mouth of the rat by plastic injection method. Okajimas Fol. A nat. Jpn., 56: 45-66, 1979.

31) Suzuki, K.: A study on the fine distribution of the gingiva and the palatine mucosa. J. Tokyo Dent. Col. Soc., 64: 705-725, 1964. (in Japanese)

32) Takashima, T.: Stereological studies on 
several ducts and vessels by injection method of acrylic resin. XIX. Arterial distribution of the submandibular gland in some mammals. Okajimas Fol. Anat. Jpn., 43: 363-383, 1967.

33) Takashima, T., T. Tokioka and M. Mizutani: Blood supply of the submandibular gland of the rat by plastic injection. Okajimas Fol. Anat. Jpn., 48: 213-220, 1971.

34) Taniguchi, Y., Y. Ohta, S. Tajiri, H. Okano and H. Hanai: Supplement to new improved method for injection of acrylic resin. Oka- jimas Fol. Anat. Jpn., 27: 401-406, 1955.

35) Watanabe, H.: The study on the asterial distribution of the mandibular bone and the dental germ in the Japanese human fetus. 2. The arterial distribution of the dental follicles by microangiogram. J. Tokyo Dent. Col. Soc., 63: 645-659, 1963. (in Japanese)

36) Yamamoto, $M$.: The arterial supply of the submandibular gland of the crabeating monkey. J. Osaka Dent. Univ., 13: 1-14, 1979.

\section{Key to abbreviations}

Md : Digastric muscle

$\mathrm{Me}$ : Geniohyoid muscle

$\mathrm{Mg}$ : Genioglossus muscle

$\mathrm{Mh}$ : Hyoglossus muscle

Mm : Mylohyoid muscle

$\mathrm{Mp}$ : Medial pterygoid muscle

G1 : Sublingual gland

$\mathrm{Gm}$ : Submandibular gland

Dm : Submandibular duct

$\mathrm{Lm}$ : Submandibular lymph node

Bh : Hyoid bone

aa : Alveolingual artery

$\mathrm{ab}:$ Alveolar branch

ca : External carotid artery

cs : Common stem

$\mathrm{db}:$ Digastric branch

fa : Facial artery

$\mathrm{gb}$ : Genioglossal branch

gg : Gingival branch gh : Geniohyoid branch

hb : Hyoid branch

hg : Hyoglossal branch

ib : Incisive gingival branch

il : Inferior labial branch

la : Lingual artery

Id : Deep lingual artery

ma : Maxillary artery

$\mathrm{mb}$ : Mylohyoid branch

$\mathrm{mg}$ : Molar gingival branch

$\mathrm{mi}$ : Median inferior labial artery

$\mathrm{mp}$ : Medial pterygoid branch

sa : Sublingual artery

sb : Sublingual glandular branch

sd : Submandibular ductal branch

sg : Submandibular glandular branch

sl : Submandibular lymph node branch

sp : Sublingual papillary branch

st : Superior thyroid artery

su : Submental artery 


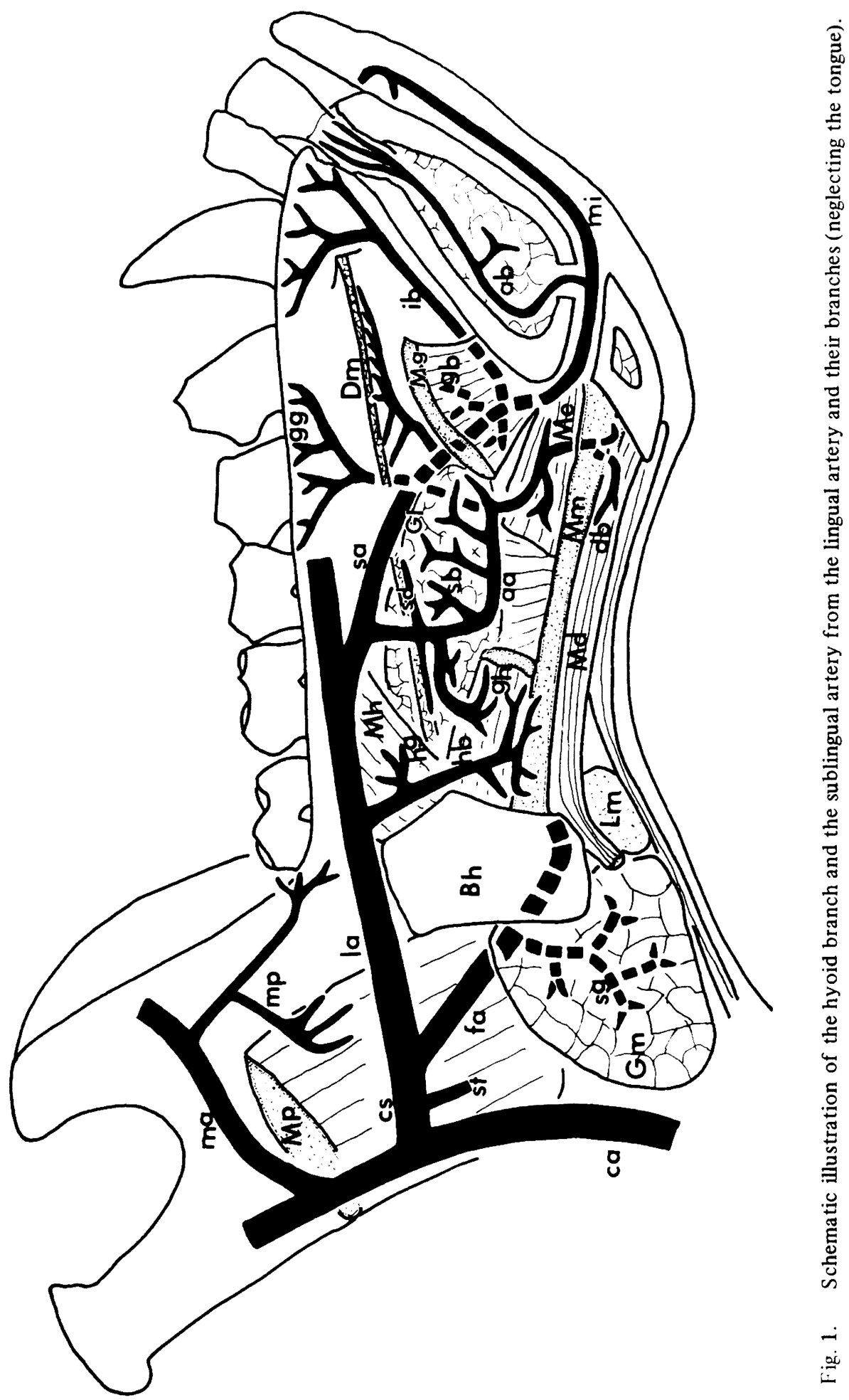




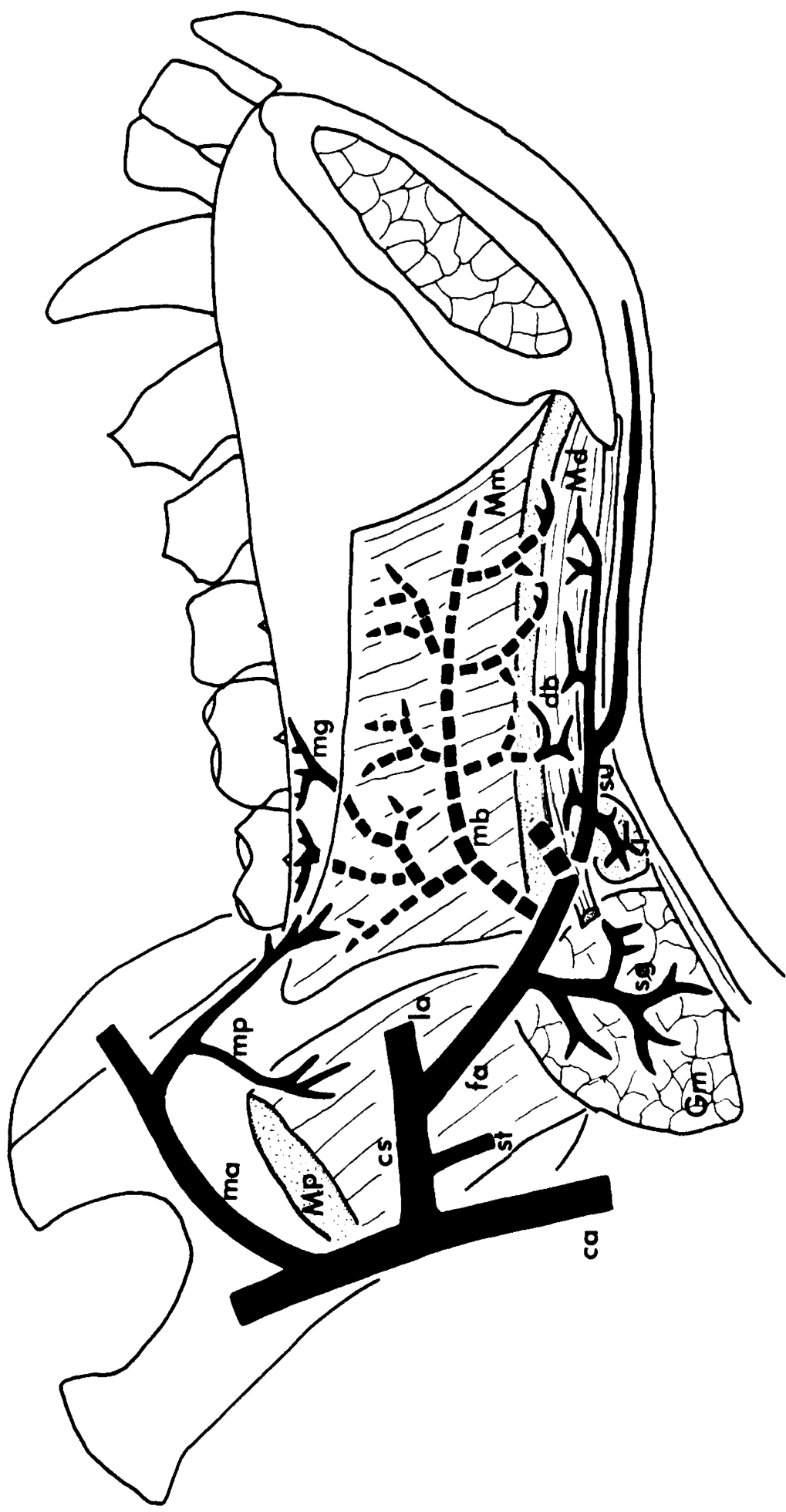




\section{Explanation of Figures}

\section{Plate I}

Fig. 3. Medial aspect of the lingual artery, the facial artery and their branchs. ca. $\times 1.8$.

Fig. 4. Medial aspect of the alveolingual artery (type II) and its branches. ca. $\times 4.4$.

Fig. 5. Medial aspect of the submandibular ductal branch from the alveolingual artery. ca. $\times 4.7$.

Fig. 6. Medial aspect of the sublingual artery and the alveolingual artery (type I). ca. $\times 2.3$. 
Plate
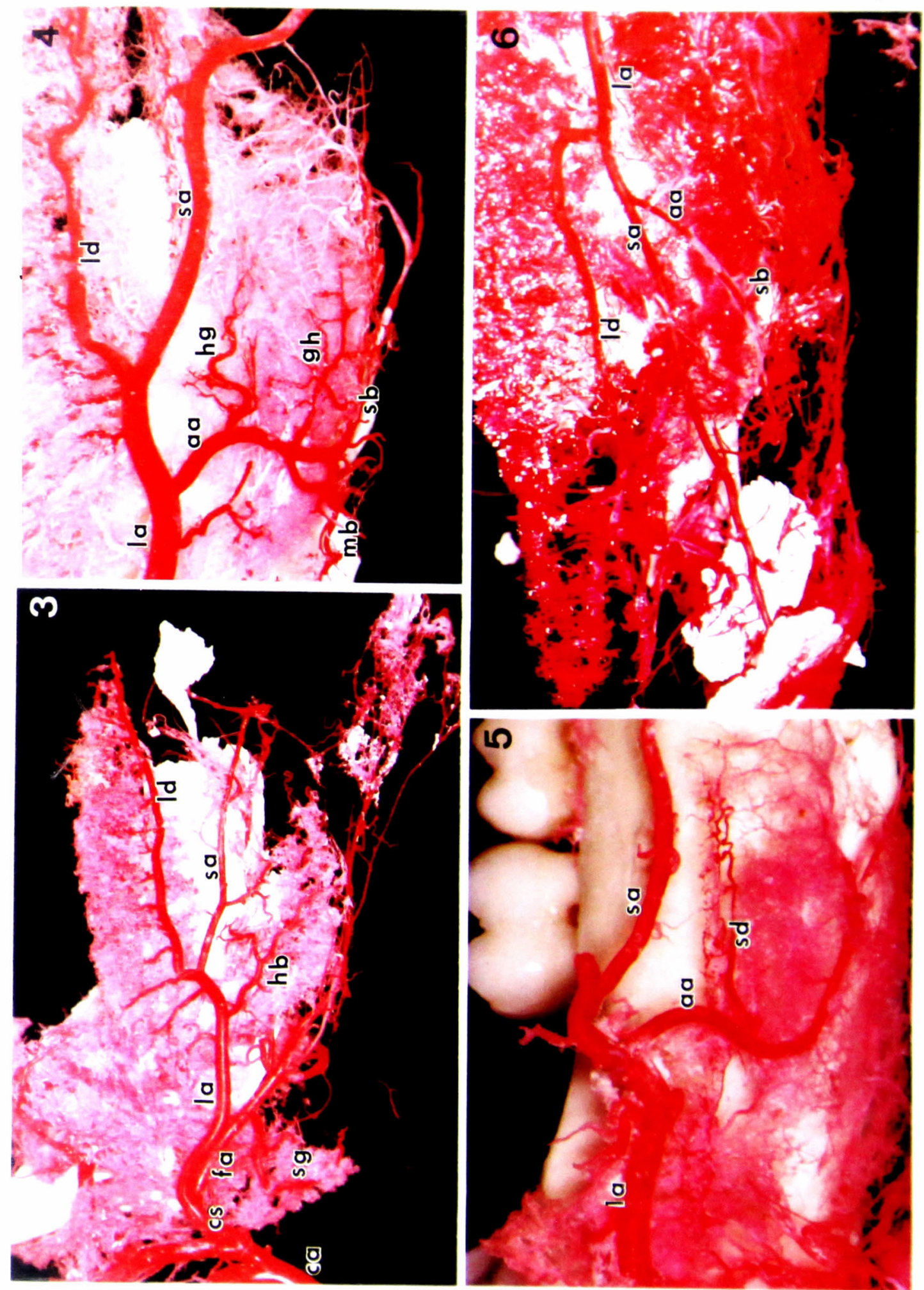


\section{Plate II}

Fig. 7. Lateral aspect of the genioglossal branches from the sublingual artery. ca. $\times 3.2$.

Fig. 8. Medial aspect of the sublingual papillary branches from the sublingual artery. ca. $\times 6.3$.

Fig. 9. Medial aspect of the incisive gingival branch from the sublingual artery. ca. $\times 4.4$.

Fig. 10. Medial aspect of the sublingual artery and its alveolar branches in the symphyseal canal. ca. $\times 3$ 

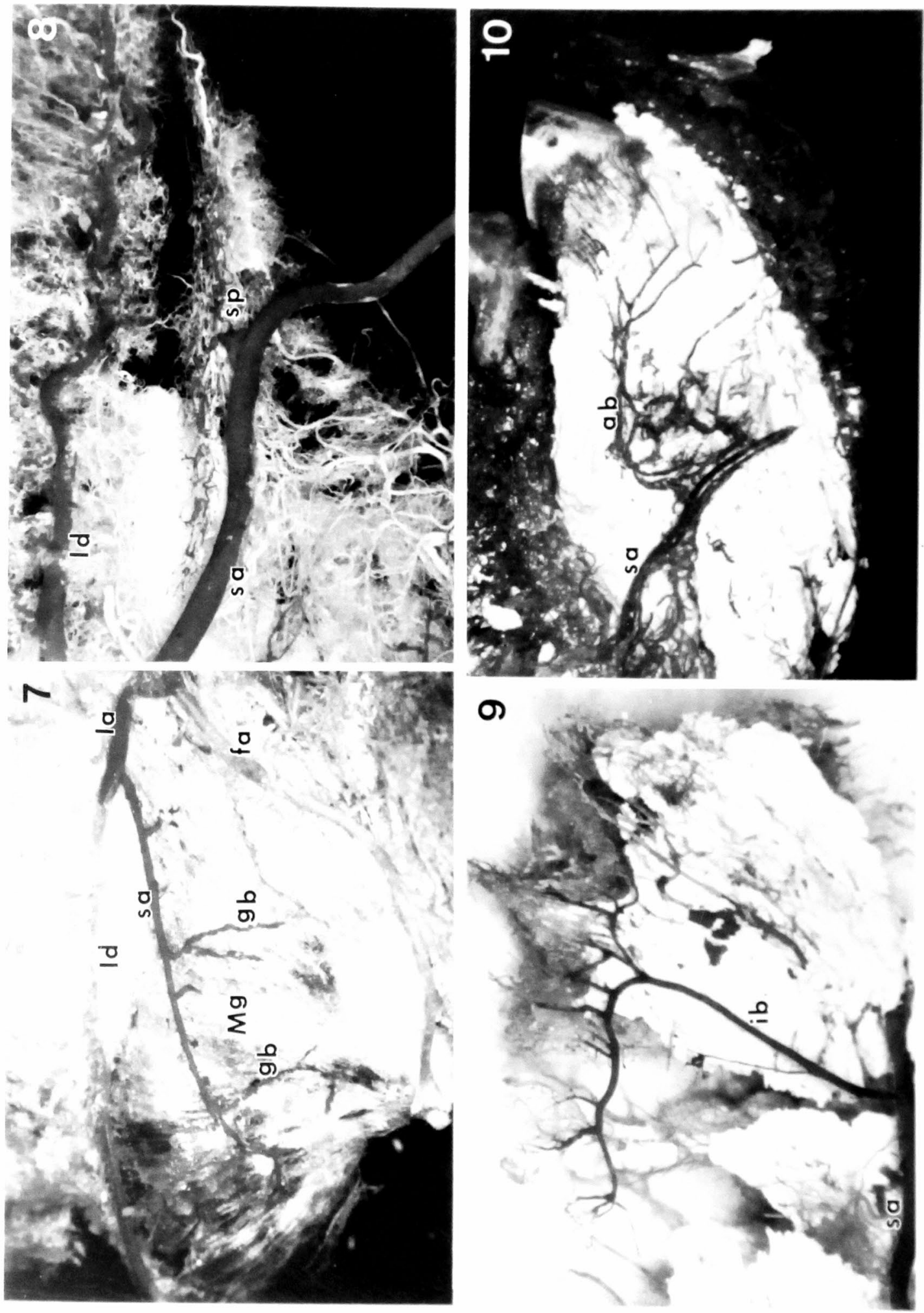


\section{Plate III}

Fig. 11. Lateral aspect of the median inferior labial artery and its branches. ca. $\times 4.6$.

Fig. 12. Medial aspect of the facial artery and its branches. ca. $\times 4$.

Fig. 13. Medial aspect of the alveolingual artery (type III) and its branches. ca. $\times 4$.

Fig. 14. Medial aspect of the mylohyoid branches from the alveolingual artery (type III). ca. $\times 6$. 
Plate III
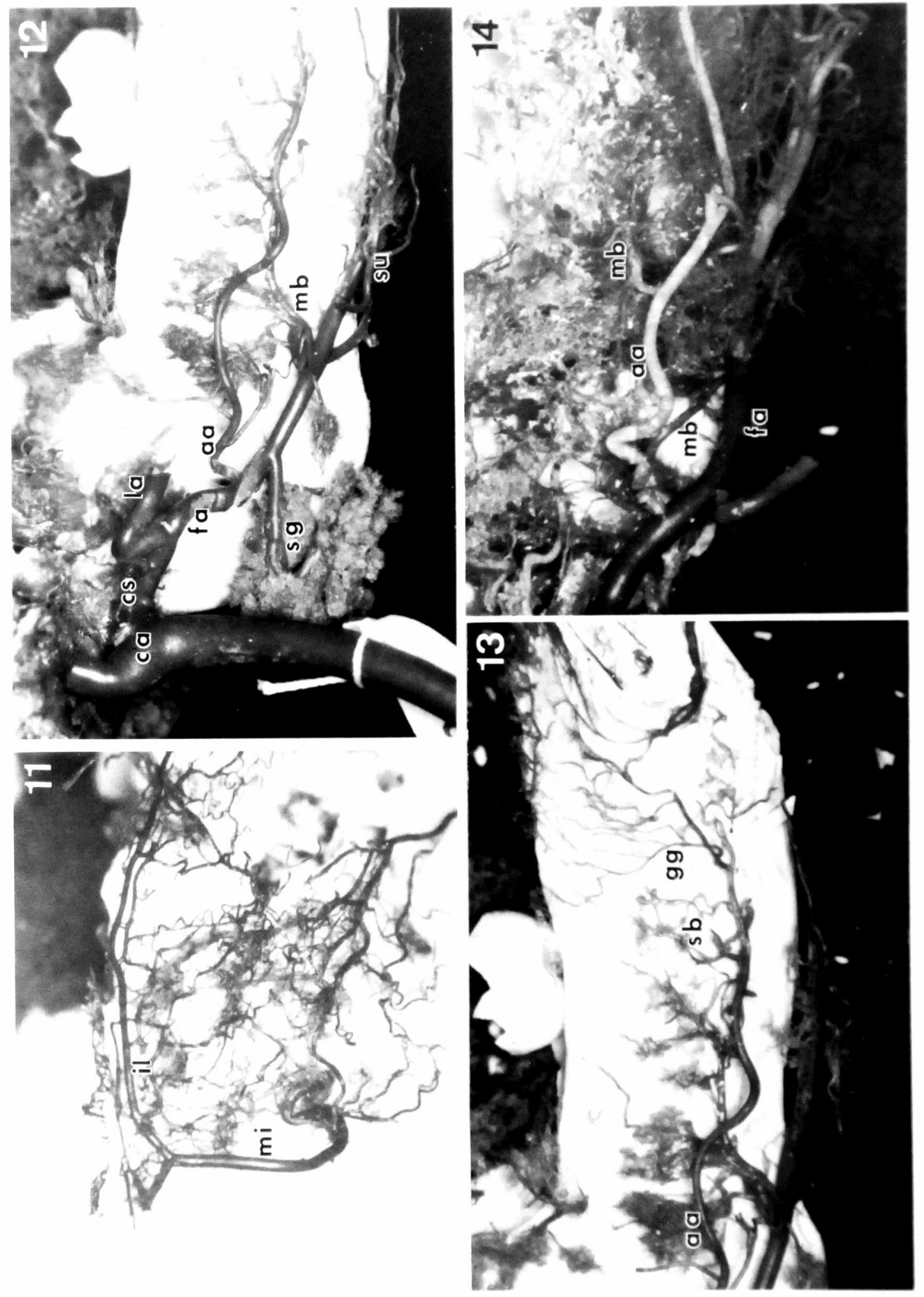


\section{Plate IV}

Fig. 15.' Medial aspect of the facial artery and the mylohyoid branch. ca. $\times 3$.

Fig. 16. Median aspect of the molar gingival branches from the mylohyoid branch. ca. $\times 3.6$.

Fig. 17. Ventral aspect of the facial artery and the submental artery. ca. $\times 4.4$.

Fig. 18. Ventral aspect of the submandibular lymph node branch from the submental artery. ca. $\times 3.4$. 
Plate IV

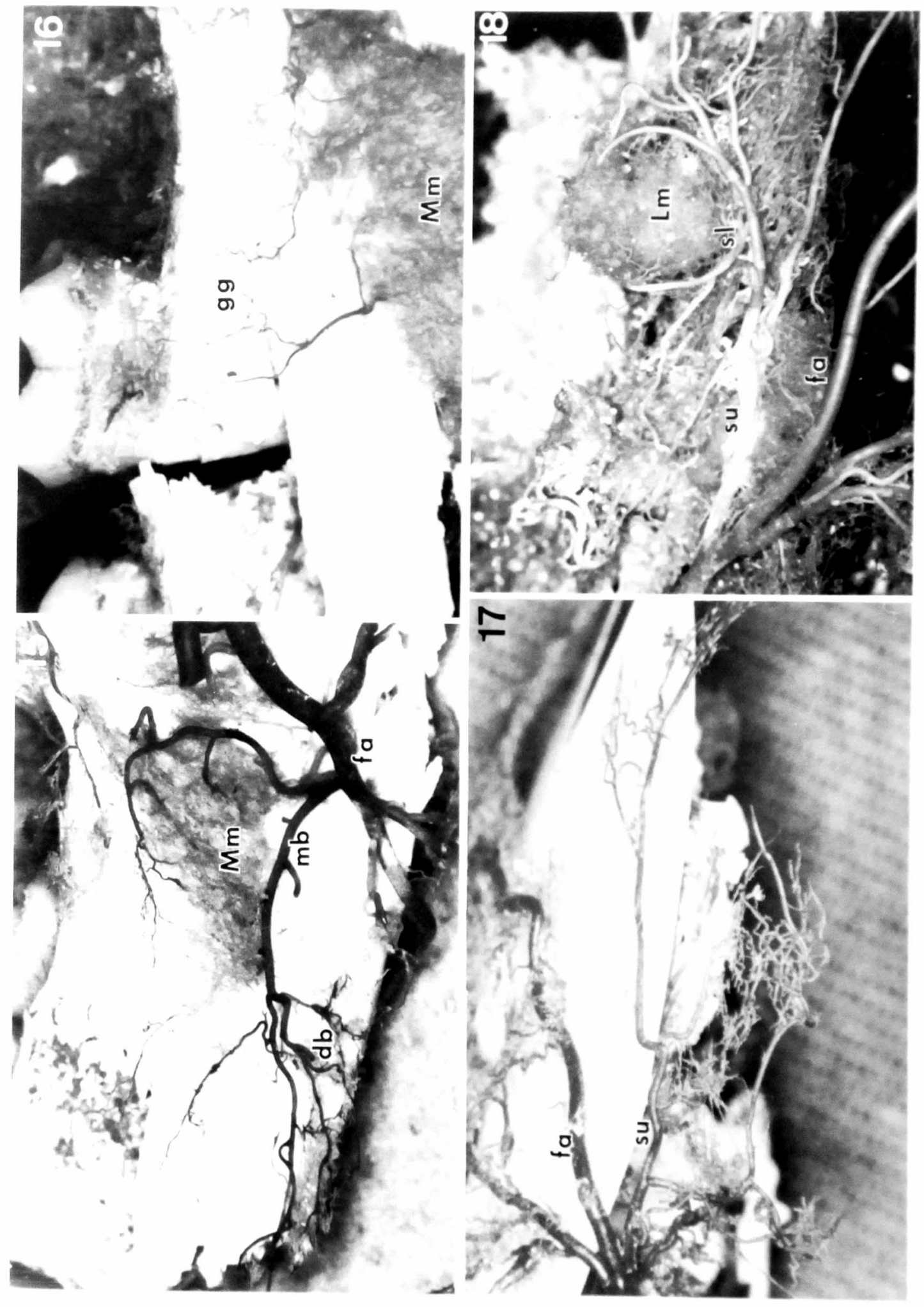




\section{Plate V}

Fig. 19. Ventral aspect of the digastric branches from the submental artery. ca. $\times 3.2$.

Fig. 20. Medial aspect of the medial pterygoid branch. ca. $\times 3.3$. 

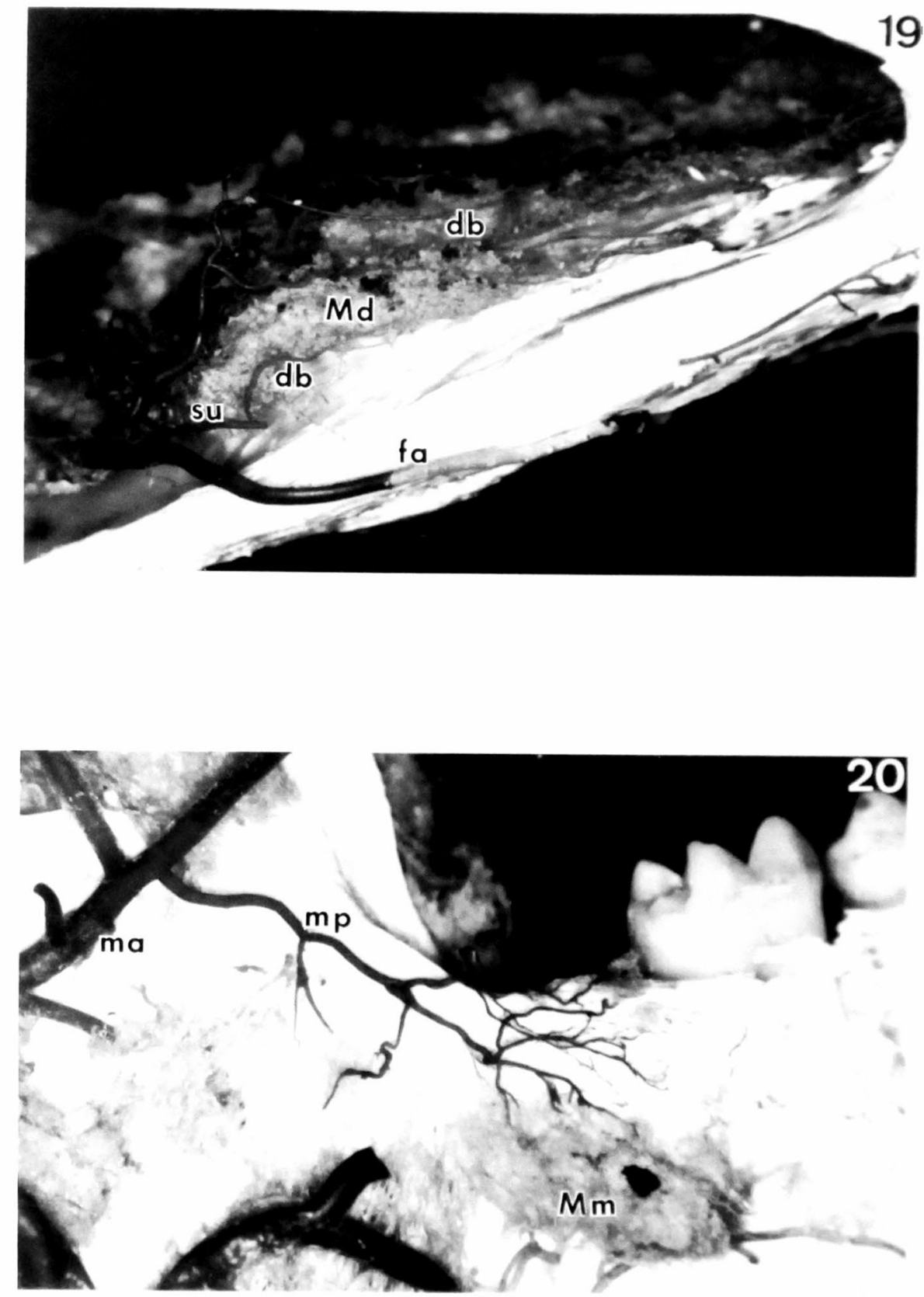